\title{
Spinal Cord Schistosomiasis: Report on Seven Adult Patients
}

\author{
Mahmoud H. Ragab1 (1), Khaled Ismail² \\ ${ }^{1}$ Department of Neurosurgery, Faculty of Medicine, Assiut University, Assiut, Egypt \\ ${ }^{2}$ Department of Neurosurgery, Faculty of Medicine, Aswan University, Aswan, Egypt \\ Email: ragabm@gmail.com
}

How to cite this paper: Ragab, M.H. and Ismail, K. (2019) Spinal Cord Schistosomiasis: Report on Seven Adult Patients. Open Journal of Modern Neurosurgery, 9 , 292-301.

https://doi.org/10.4236/ojmn.2019.93028

Received: April 23, 2019

Accepted: July 1, 2019

Published: July 4, 2019

Copyright (๑) 2019 by author(s) and Scientific Research Publishing Inc. This work is licensed under the Creative Commons Attribution International License (CC BY 4.0).

http://creativecommons.org/licenses/by/4.0/

\begin{abstract}
Background: Spinal Cord Schistosomiasis (SCS) is the most disabling ectopic form of Schistosomal infection. It may or may not have clinical manifestations. They include low back pain and/or lower limb pain and weakness, and double incontinence. Early diagnosis and treatment provide a good outcome. Aim: To describe the clinical, radiologic, and therapeutic data of 7 patients with Spinal Schistosomiasis. Patients and Methods: In this retrospective clinical case study, the medical records of 7 patients with spinal cord pathologies admitted to Aswan University Hospital from May 2014 to May 2017 were reviewed. All were male aged from 17 to 30 years old (mean \pm SD, $20 \pm 9.5$ yr.; median 21 yr.), with neurological deficit in the form of lower limb weakness and sphincter disturbance. All were treated by decompressive laminectomy and debulking of the intramedullary lesion followed by medical treatment. Results: The outcome of our patients was good as 4/7 patients (57\%) presented a full recovery, $3 / 7$ patients $(43 \%)$ presented a partial recovery without functional limitations and none presented a partial recovery with limitations or no response. Conclusion: High index of suspicion should be raised in the differential diagnosis of patients with clinical or radiological evidence of Spinal Cord Schistosomiasis, as early diagnosis can guarantee a better prognosis and avoid the occurrence of serious sequels. The association of corticosteroids and antischistosomal drugs is related to the best outcome. The role of surgery is decompression, particularly in the granulomatous or pseudotumoral form, and to obtain material for definite histopathological diagnosis in doubtful cases.
\end{abstract}

\section{Keywords}

Antischistosomal Drugs, Neuroschistosomiasis, Spinal Cord Schistosomiasis 


\section{Introduction}

Schistosomiasis is a disease caused by trematode worms belonging to the Schistosoma genus. There are many species that affect man in different clinical presentations. The three main species of schistosomes: Schistosoma mansoni, Schistosoma haematobium and Schistosoma japonicum can affect the central nervous system (CNS). The first human case of neurological lesion caused by Schistosoma was described in 1889 by Yamagiwa in the cerebral autopsy of a patient with epilepsy. In 1905, Shimamura and Tsunoda demonstrated the first Schistosomal myelopathy caused by Schistosoma japonicum in a patient with transverse myelitis. In 1930, Muller and Stender described the first Schistosomal myelopathy caused by Schistosoma mansoni in a 26-year-old man who had been to Brazil. In 1948, Faust published a review on 82 patients with ectopic Schistosomiasis from them: 56 patients had cerebral Schistosomiasis and 8 patients had spinal cord Schistosomiasis [1]. Spinal cord Schistosomiasis (SCS) affects individuals of all ages, as cases between one and 68 years old have been reported with the average age being 26 years [2]. The incidence of Spinal cord Schistosomiasis is higher amongst males than females, and this has been explained by man's higher occupational exposure [3].

The worms and eggs reach the spinal cord within the retrograde venous flow in the valveless Batson's vertebral venous plexus, which connects the portal venous system and the inferior vena cava to the spinal veins especially during raised intrabdominal pressure [4]. It has been shown that Schistosoma japonicum eggs are often found in the brain, whilst those of Schistosoma mansoni are found in the lower zones of the spinal cord. And this has been explained by that the eggs of Schistosoma japonicum are smaller and more easily reach the brain, whereas Schistosoma mansoni and Schistosoma haematobium eggs are larger and may be retained much more frequently in the spinal cord [5]. SCS may be asymptomatic, diagnosed through necropsy studies, or symptomatic. Most patients have no clinical evidence of hepatosplenic schistosomiasis and the diagnosis is often made following Spinal cord damage [6]. SCS typical clinical triad which is found in more than $90 \%$ of patients is diminishing of muscular strength, sensory alterations in the lower limbs and bladder dysfunction [7] [8]. The diagnosis of SCS was suspected through the clinical picture associated with a positive epidemiological history. Although the absence of Schistosomal eggs in urine or stool does not exclude an SCS diagnosis, stool and urine examinations for Schistosomal eggs should be considered in all suspected patients [6]. The neuroimaging has a great value in the diagnosis, although they are not specific and even when normal do not exclude the diagnosis. The MRI may show important data about the location and extension of the lesion and ruling out tumorous lesions. A CT has a lower sensibility but may show increased cord volume [9]. The treatment of SCS is clinical and is made with schistosomicides associated with corticosteroids, the latter counters the granulomatous inflammation and can result in rapid improvement [10]. Surgical laminectomy and biopsy 
with spinal cord decompression is indicated for doubtful cases and in patients with mass lesion and neurological deficits [11].

In this study, we report the preoperative characteristics of 7 surgically confirmed patients of spinal cord Schistosomiasis and correlate them with the surgical outcome and pathological findings aiming to emphasize that a high index of suspicion should be raised in the differential diagnosis of transverse myelitis in endemic areas.

\section{Patients and Methods}

In this retrospective clinical case study, the medical records of 7 patients with spinal cord pathologies admitted to Aswan University Hospital from May 2014 to May 2017 were reviewed.

Inclusion criteria:

Patients with definite histopathological diagnosis of spinal cord schistosomiasis.

\section{Exclusion criteria:}

Patients with other causes of transverse myelitis than schistosomiasis.

Patients who refused surgical interference when indicated.

Patients with unavailable clinical or radiological data.

Patients who were lost during follow-up.

The socio-demographic and clinical characteristics of the patients at admission were studied and analyzed. Initial neuroimaging study of the patients was performed through MRI which was repeated after 3-month follow-up and the outcome was defined.

All patients were males. Their ages ranged from 17 to 30 years old (mean \pm SD, $21 \pm 9.5$ yr.; median $20 \mathrm{yr}$ ). All were farmers with a positive history of contact with natural water was present in all of them All patients were presented by low back pain with paraparesis and urinary retention of acute/subacute progression. All patients had urine examination for Schistosomal eggs demonstration but all yield negative results. Magnetic resonance imaging (MRI) of the dorsal-lumbar spine with and without contrast was done to all patients, as it is the investigation of choice in spinal cord lesions. The most frequent findings are enlargement of the conus medullaris and thickening of the cauda equina roots with a heterogeneous pattern of contrast enhancement. In all patients, spinal lesions were surgically managed through decompressive laminectomy and either biopsy or debulking. Histopathological examination for the obtained specimens was done to show a granulomatous inflammation surrounding bilharzial ova with a final diagnosis of spinal cord schistosomiasis. After definite histopathological diagnosis, specific medical treatment with steroids and anti-bilharzial drugs has been commenced and lead to marked improvement in clinical presentation. Follow up, clinical and neuroimaging, was done 3 months post-operative. Outcome was defined as: 1) full recovery when the patient presented complete recovery of his neurological status; 2) partial recovery without functional limita- 
tions when the patient remained with only minor deficits that did not interfere with daily activities; 3 ) partial recovery with limitations or no recovery if the patient did not show any improvement or was left with permanent disabling weakness or sensory loss.

\section{Results}

The socio-demographic and clinical characteristics of our 7 patients were remarkably similar (Table 1). All patients were males. Their ages ranged from 17 to 30 years old (mean \pm SD, $21 \pm 9.5$ yr.; median 20 yr.). The clinical characteristics were in the form of paresthesia and weakness in lower limbs, lumbar and/or lower limb pain, and incontinence of urine. Lower limbs weakness and urine retention were most prominent in the pseudotumoral form of the disease (cases 1 , 2,3 , and 4), whereas lower limbs pain and incontinence were more frequent in the myeloradicular form of the disease (cases 5, 6, and 7). The search for schistosomal eggs in both urine and stool was carried for all patients and yielded negative results. None of our patients had hepatosplenomegaly or portal hypertension. CSF analysis was not done. All patients were submitted to MRI examination with the most frequent findings were Fusiform enlargement of the cord, contrast enhancement on T1-weighted images in the pseudotumoral form (cases 1, 2, 3, and 4), and Nodular and peripheral enhancement of the conus and lepto-meninges and contrast enhancement after gadolinium injection in the myeloradicular form (cases 5, 6, and 7). Decompressive laminectomy and either biopsy or debulking were done for all patients with grayish yellow irregularly expanded cord in the pseudotumoral form (cases 1, 2, 3, and 4) and gliotic yellow rim nodules in the myeloradicular form (cases 5, 6, and 7). Histopathological examination showed a granulomatous inflammation, lymphocytic infiltrate and fibrosis surrounding bilharzial ova with a final diagnosis of spinal cord schistosomiasis (Figure 1). Therapeutic regimen in our study was based on the association of an anti-schistosomal drug (praziquantel $40-60 \mathrm{mg} / \mathrm{kg}$ in divided doses for 3 days), preceded by a steroid therapy (methylprednisone $0.5 \mathrm{~g}$ for 3 - 5 days followed by prednisone $1 \mathrm{mg} / \mathrm{kg}$ for a total duration of $3-6$ months). The outcome of our patients was good as $4 / 7$ patients (57\%) presented a full recovery to treatment, $3 / 7$ patients $(43 \%)$ presented a partial recovery without functional limitations and none of our patients presented a partial recovery with limitations or no response. MRI done after three months revealed resolution of conus medullaris lesion.

Case report-A 20 years old male patient presented with a subtle picture of paresthesia in the lower limbs followed by a burning low-back pain. One week later he complained paraparesis that progressed to paraplegia in two week and disturbed function in the bowel and bladder. The patient was admitted to Aswan University Hospital and the socio-demographic and clinical data were collected and analyzed. He was a farmer lived in a rural area with a positive history of contact with natural water. The neurologic examination showed lower limbs 
weakness, diminished tactile sensation and absent deep tendon reflexes at the knee and ankle. Magnetic Resonance Imaging was performed to show enlargement of the spinal cord from T11 to L2, contrast enhancement on T1-weighted images, and inhomogeneous high signal intensity in the enlarged portion of the cord on T2-weighted images Figure 2. The patient was taken to the operating room. Laminectomy from T11 to L2 was performed, with subtotal resection of a soft yellow mass. Pathologic examination showed granulomatous inflammation containing Schistosoma hematobium ova. The patient was treated with (praziquantel $40-60 \mathrm{mg} / \mathrm{kg}$ in divided doses for 3 days), preceded by a steroid therapy (methylprednisone $0.5 \mathrm{~g}$ for 3 - 5 days). At discharge, the patient showed improved lower limbs power and was able to ambulate with a walking aid. Six months later, the patient was ambulatory with resolution of his neurogenic bladder and with only minimal residual weakness of the hip flexors.

\section{Discussion}

Spinal cord Schistosomiasis may be an important underrecognized cause of acute myelopathy in endemic countries. Most cases of spinal schistosomiasis are due Schistosoma Mansoni although Schistosoma Haematobium has been isolated [12] [13]. The incidence of Spinal cord Schistosomiasis is higher amongst young aged males than females [3], and this has been explained by young man's higher occupational exposure. Some reported variable results with Schistosoma mansoni peak age at 28 year and Schistosoma haematobium peak age at 19 year [14].

Table 1. The socio-demographic and clinical characteristics of our 7 patients.

\begin{tabular}{|c|c|c|c|c|c|}
\hline & Age/Sex & Clinical Picture & MRI findings & Operative findings & outcome \\
\hline $\mathrm{Pt}(1)$ & $17 / \mathrm{M}$ & $\begin{array}{l}\text { Paraparesis/Paraesthesia/ } \\
\text { Retention }\end{array}$ & $\begin{array}{l}\text { Fusiform enlargement of the cord, contrast } \\
\text { enhancement on T1-weighted images }\end{array}$ & $\begin{array}{l}\text { grayish yellow } \\
\text { irregularly expanded } \\
\text { cord }\end{array}$ & full recovery \\
\hline $\mathrm{Pt}(2)$ & $18 / \mathrm{M}$ & $\begin{array}{l}\text { RT lower limb weakness/ } \\
\text { Retention }\end{array}$ & $\begin{array}{l}\text { Fusiform enlargement of the cord, contrast } \\
\text { enhancement on T1-weighted images }\end{array}$ & $\begin{array}{l}\text { grayish yellow } \\
\text { irregularly expanded } \\
\text { cord }\end{array}$ & full recovery \\
\hline $\mathrm{Pt}(3)$ & 19/M & $\begin{array}{l}\text { Rt lower limb pain and } \\
\text { weakness/Retention }\end{array}$ & $\begin{array}{l}\text { Fusiform enlargement of the cord, contrast } \\
\text { enhancement on T1-weighted images }\end{array}$ & $\begin{array}{l}\text { grayish yellow } \\
\text { irregularly expanded } \\
\text { cord }\end{array}$ & full recovery \\
\hline Pt (4) & $20 / \mathrm{M}$ & $\begin{array}{l}\text { Paraparesis/Paraesthesia/ } \\
\text { Retention }\end{array}$ & $\begin{array}{l}\text { Fusiform enlargement of the cord, contrast } \\
\text { enhancement on T1-weighted images }\end{array}$ & $\begin{array}{l}\text { grayish yellow } \\
\text { irregularly expanded } \\
\text { cord }\end{array}$ & full recovery \\
\hline Pt (5) & $21 / \mathrm{M}$ & $\begin{array}{l}\text { Rt lower limb pain and weakness/ } \\
\text { Paraesthesia/incontinence }\end{array}$ & $\begin{array}{l}\text { Nodular and peripheral enhancement of the } \\
\text { conus and lepto-meninges }\end{array}$ & $\begin{array}{l}\text { gliotic yellow rim } \\
\text { nodules }\end{array}$ & $\begin{array}{l}\text { partial recovery } \\
\text { without functional } \\
\text { limitations }\end{array}$ \\
\hline Pt (6) & $22 / \mathrm{M}$ & $\begin{array}{l}\text { Bilateral lower limb pain and } \\
\text { weakness/Paraesthesia/ } \\
\text { incontinence }\end{array}$ & $\begin{array}{l}\text { Nodular and peripheral enhancement of the } \\
\text { conus and lepto-meninges }\end{array}$ & $\begin{array}{l}\text { gliotic yellow rim } \\
\text { nodules }\end{array}$ & $\begin{array}{l}\text { partial recovery } \\
\text { without functional } \\
\text { limitations }\end{array}$ \\
\hline $\mathrm{Pt}(7)$ & $30 / \mathrm{M}$ & $\begin{array}{l}\text { Lt lower limb pain and } \\
\text { weakness/Paraesthesia/ } \\
\text { incontinence }\end{array}$ & $\begin{array}{l}\text { Nodular and peripheral enhancement of the } \\
\text { conus and lepto-meninges }\end{array}$ & $\begin{array}{l}\text { gliotic yellow rim } \\
\text { nodules }\end{array}$ & $\begin{array}{l}\text { partial recovery } \\
\text { without functional } \\
\text { limitations }\end{array}$ \\
\hline
\end{tabular}




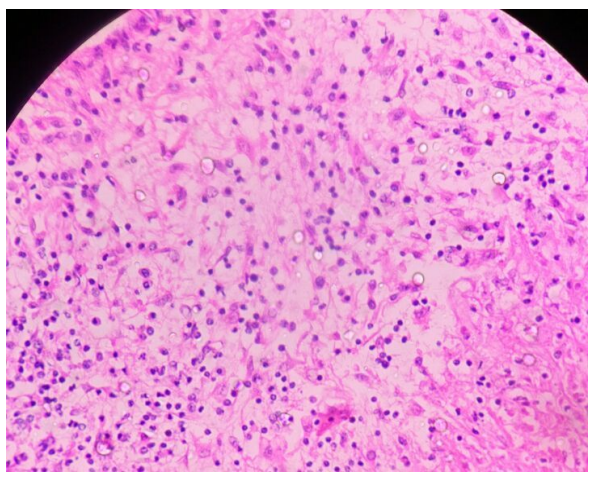

Figure 1. Microscopic examination of SCS showing focal deposition of bilharzial ova surrounded by lymphocytic infiltrate and fibrosis.

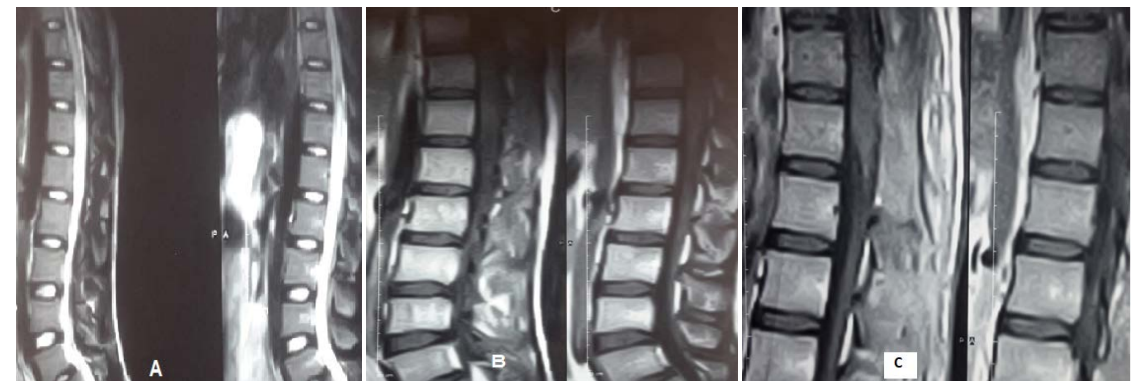

Figure 2. MRI of the dorsal lumber spine. (A) Preoperative T2 sagittal view with hyperintense fusiform cord enlargement; (B) Preoperative T1 contrast sagittal view with hyperintense fusiform cord enlargement; (C) Postoperative sagittal T1 MRI with contrast with laminectomy from T11-L2.

Spinal cord Schistosomiasis may be asymptomatic, diagnosed through necropsy studies, or symptomatic. Spinal cord Schistosomiasis presents in three clinic forms: myelitic form, granulomatous form; and radicular or myeloradicular form [1] [15]. Four of our patients presented in the granulomatous (pseudotumoral) form namely lower limbs weakness and urine retention (4/7-57\%) and three in the myeloradicular form namely pain in the lower limbs and incontinence $(3 / 7-43 \%)$.

Some authors reported the predominance of the myeloradicular form over the granulomatous form [16] while others indicated the predominance of the granulomatous form specially in children and attributed this to the immunological state [17]. Although some reported the clinical evidence of hepatosplenic schistosomiasis, none of our patients had such clinical evidence [6] [18]. Spinal cord Schistosomiasis typical clinical triad is diminishing of muscular strength, sensory alterations in the lower limbs and bladder dysfunction. [7] [8].

The neurological symptoms are caused by the cellular immune reaction of the host around the eggs and the formation of granulomatous masses localized in conus medullaris, lower thoracic spinal cord and spinal lumbar and sacral nerve roots. The progression of symptoms may be the result of two factors: de novo egg deposition and the host's inflammatory response to the excretion of antigen protein by the embryo [19]. 
None of our patients showed positive results regarding schistosomal eggs during the search for eggs in urine and stool examination. Some reported positive result both in adults and children [6] [17] [18]. Thus, the absence of schistosomal eggs in urine or stool does not exclude a Spinal cord Schistosomiasis diagnosis.

The neuro-imaging have a great value in the diagnosis of SCS. MRI of the spinal cord provides valuable information to assess the location and extension of spinal granulomas, and the degree of spinal inflammation, necrosis and edema [9]. The most frequent findings are enlargement of the conus medullaris and thickening of the cauda equina roots with a heterogeneous pattern of contrast enhancement. Typically, there is edema of the spinal cord, conus medullaris and cauda equina. Intramedullary schistosomal granuloma may show moderate expansion of the distal cord, isointense relative to the cord, a heterogeneous hyperintense lesion with an unclear boundary, or multiple patchy nodular lesions resembling a string of beads mainly in the ventral spinal cord which may be significantly enhanced. Atrophy of the spinal cord may also be found in longstanding cases [9].

Clinically spinal schistosomiasis may mimic a chronic progressive paraparesis and radiologically (on MRI) it may mimic an expanding spinal tumor. Cases of children with Schistosoma haematobium tumor-like spinal lesion, initially diagnosed as a cord neoplasm, have been reported [20].

Several serological techniques in serum and cerebrospinal fluid have been developed to detect antibodies against schistosome crude egg and soluble worm antigens. ELISA, haemagglutination and/or indirect immunofluorescence have been used, although they have variable degrees of sensitivity and specificity. The ELISA technique for detection of soluble egg antigen has high sensitivity and specificity and is a reliable method. The combination of ELISA and haemagglutination has $90 \%$ sensitivity and $93 \%$ specificity in the diagnosis of schistosomiasis japonica [21].

A definitive diagnosis can only be made by means of histopathological study demonstrating granulomatous inflammation, lymphocytic infiltrate and fibrosis surrounding schistosomal eggs. Biopsy of spinal cord, though not feasible option, may show schistosome ova in various stages of evolution, with surrounding inflammatory reaction and demyelination near the ova [22].

Differential diagnosis of spinal schistosomiasis should include ependymoma, spinal cord astrocytoma, metastatic tumor, spinal dural arteriovenous fistula and spinal neurocysticercosis. SCS shows less anatomic distortion than intramedullary tumors [9] [11].

Analysis of the literature showed that the association of antischistosomal drugs and corticosteroids is related to the best outcome [18]. Laminectomy and intraoperative biopsy is indicated only for doubtful cases and for cord decompression in patients with granulomatous form [23].

Therapeutic regimen in our study was based on the association of an anti-schistosomal drug (praziquantel $40-60 \mathrm{mg} / \mathrm{kg}$ in divided doses for 3 days), 
preceded by a steroid therapy (methylprednisone $0.5 \mathrm{~g}$ for 3 - 5 days followed by prednisone $1 \mathrm{mg} / \mathrm{kg}$ for a total duration of 3 - 6 months) preceded by spinal cord decompression and debulking.

Praziquantel (antibilharzial drug) is effective against adult schistosome worms. This drug provokes parasite tegument disruption, depletes the glutathione content and affects the calcium channel function [24].

Corticosteroids are used to suppress the inflammatory response and granuloma formation, thereby preventing further tissue destruction, and reduce ova deposition [25].

However, to the best of our knowledge no clinical trial has been published comparing the efficacy of spinal surgical intervention against the best pharmacological treatment. The combination of surgical decompression plus antibilharzial drugs and steroids should be indicated only in selected patients presenting with rapid deterioration of lower limb strength and evidence of extra-axial spinal cord compression due to tumor-like lesions [26].

All patients living in endemic areas or with a history of schistosomal exposure and clinical or radiological evidence of myeloradiculopathy should be treated promptly as Schistosomiasis of the spinal cord is potentially curable if diagnosed and managed early.

This study has many limitations as it has been conducted in one center, small patients sample size, and short follow-up time. Future recommendation includes multicentric large sample size studies.

\section{Conclusion}

In Endemic areas, a high index of suspicion should be raised in the differential diagnosis of patients with clinical or radiological evidence of spinal cord pathology. Though uncommon, spinal schistosomiasis is an important and potentially treatable cause of myelopathy. The association of corticosteroids and antischistosomal drugs is related to the best outcome. The addition of surgical decompression to antischistosomal drugs and steroids should be indicated only in selected patients presenting with rapid deterioration in the motor function of lower limbs and evidence of spinal cord compression due to tumor-like lesions. Even though surgery should involve minimal procedures to avoid neural tissues damage. Clinical trials are necessary to confirm the dose and length of Schistosomicidal treatment course and the efficacy of add-on surgical procedures.

\section{Conflicts of Interest}

The authors declare no conflicts of interest regarding the publication of this paper.

\section{References}

[1] Faust, E.C. (1948) An Inquiry into the Ectopic Lesions in Schistosomiasis. The American Journal of Tropical Medicine and Hygiene, 28, 175-199.

https://doi.org/10.4269/ajtmh.1948.s1-28.175 
[2] Silva, L.C.S., Maciel, P.E., Ribas, J.G., et al. (2004) Schistosomal Myeloradiculopathy. Revista da Sociedade Brasileira de Medicina Tropical, 37, 261-272. https://doi.org/10.1590/S0037-86822004000300013

[3] Van Leusen, H. and Perquin, W.V.M. (2000) Spinal Cord Schistosomiasis. Journal of Neurosurgery and Psychiatry, 69, 690-691. https://doi.org/10.1136/jnnp.69.5.690

[4] Scrimgeour, E.M. and Gajdusek, D.C. (1985) Involvement of the Central Nervous System in Schistosoma mansoni and Schistosoma haematobium Infection. Brain, 108, 1023-1038. https://doi.org/10.1093/brain/108.4.1023

[5] Liu, L.X. (1993) Spinal and Cerebral Schistosomiasis. Seminars in Neurology, 13, 189-200. https://doi.org/10.1055/s-2008-1041125

[6] Peregrino, A.J.P., Oliveira, S.P., Porto, C.A., et al. (1988) Meningomieloradiculite por Schistosoma mansoni, protocolo de investigação e registro de 21 casos. Arquivos de Neuro-Psiquiatria, 46, 49-60.

https://doi.org/10.1590/S0004-282X1988000100009

[7] Freitas, A.R.R., Oliveira, A.C.P. and Silva, L.J. (2010) Schistosomal Myeloradiculopathy in a Low-Prevalence Area: 27 Cases (14 Autochthonous) in Campinas, Sao Paulo, Brazil. Memórias do Instituto Oswaldo Cruz, 105, 398-408.

https://doi.org/10.1590/S0074-02762010000400009

[8] Araújo, K.C., Silva, C.R. and Santos, A.G. (2010) Clinical-Epidemiologic Profile of the Schistosomal Myeloradiculopathy in Pernambuco, Brazil. Memórias do Instituto Oswaldo Cruz, 105, 454-459. https://doi.org/10.1590/S0074-02762010000400017

[9] Henriques Souza, A.M. and Valença, M.M. (2011) Schistosomal Myelopathy in Childhood: Findings of Magnetic Resonance Imaging in 26 Patients. Pediatric Neurology, 45, 373-376. https://doi.org/10.1016/j.pediatrneurol.2011.09.006

[10] Nazer, H., Hugosson, C. and Posas, H. (1993) Transverse Myelitis in a Child with Down's Syndrome and Schistosomal Colitis. Annals of Tropical Paediatrics, 13, 353-357. https://doi.org/10.1080/02724936.1993.11747670

[11] Luyendijk, W. and Lindeman, J. (1975) Schistosomiasis (Bilharziasis) Mansoni of the Spinal Cord Simulating an Intramedullary Tumor. Surgical Neurology, 4, 457-460.

[12] El Banhawy, A., Elwan, O. and Taher, Y. (1972) Bilharzial Granuloma of the Conus Medullaris and Cauda Equina. Paraplegia, 10, 172-180. https://doi.org/10.1038/sc.1972.29

[13] Elkhayat, R.A. and Girgis, M. (1993) Bilharzial Granuloma of the Conus; Case Report. Neurosurgery, 32, 1022-1024. https://doi.org/10.1097/00006123-199306000-00024

[14] Mahmoud, A.A.F. (1987) Trematodes and Other Flukes. In: Mandell, G.L., et al., Eds., Principles and Practice of Infectious Diseases, 3rd Edition, John Wiley and Sons, New York, 2145-2151.

[15] Bird, A.V. (1965) Spinal Cord Complications of Bilharziasis. South African Medical Journal, 20, 158-162.

[16] José, A.P., Marcelo, V., Erasmo, B.C., et al. (2002) Spinal Cord Schistosomiasis in Children; Analysis of Seven Cases. Arquivos de Neuro-Psiquiatria, 60, 224-230. https://doi.org/10.1590/S0004-282X2002000200007

[17] Salomão, J.F., Duarte, F., Ancilon, M., et al. (1987) Esquistossomose medular forma tumoral: Relato de um caso. Arquivos de Neuro-Psiquiatria, 45, 312-323. https://doi.org/10.1590/S0004-282X1987000300012

[18] Galvão, A.C.R. (1985) Radiculomielopatias esquistossomóticas. Arquivos Brasileiros 
de Neurocirurgia, 4, 133-139.

[19] Ferrari, T.C., Moreira, P.R. and Cunha, A.S. (2004) Spinal Cord Schistosomiasis: A Prospective Study of 63 Cases Emphasizing Clinical and Therapeutic Aspects. Journal of Clinical Neuroscience, 11, 246-253. https://doi.org/10.1016/j.jocn.2003.05.006

[20] Crowell, C., Kiruga, J.M. and Figaji, A. (2011) Neuroschistosomiasis Due to Schistosoma haematobium Presenting as Spinal Cord Tumor. The Pediatric Infectious Disease Journal, 30, 1006-1008. https://doi.org/10.1097/INF.0b013e31822769bd

[21] Zhu, H., Yu, C. and Xia, X. (2010) Assessing the Diagnostic Accuracy of Immunodiagnostic Techniques in the Diagnosis of Schistosomiasis japonica: A Meta-Analysis. Parasitology Research, 5, 1067-1073.

https://doi.org/10.1007/s00436-010-1970-3

[22] Carod Artal, F.J., Mesquita, H.M. and Gepp, R.A. (2006) Brain Involvement in a Schistosoma mansoni Myelopathy Patient. Journal of Neurology, Neurosurgery, and Psychiatry, 77, 512. https://doi.org/10.1136/jnnp.2005.078014

[23] Scrimgeour, E.M. and Gajdusek, D.C. (1985) Involvement of the Central Nervous System in Schistosoma mansoni and Schistosoma haematobium Infection. Brain, 108, 1023-1038. https://doi.org/10.1093/brain/108.4.1023

[24] Doenhoff, M.J., Cioli, D. and Utzinger, J. (2008) Praziquantel: Mechanisms of Action, Resistance and New Derivatives for Schistosomiasis. Current Opinion in Infectious Diseases, 21, 659-667. https://doi.org/10.1097/QCO.0b013e328318978f

[25] Fowler, R., Lee, C. and Keytone, J.S. (1999) The Role of Corticosteroids in the Treatment of Cerebral Schistosomiasis Caused by Schistosoma mansoni: Case Report and Discussion. The American Journal of Tropical Medicine and Hygiene, 61, 47-50. https://doi.org/10.4269/ajtmh.1999.61.47

[26] Salim, A.D., Arbab, M.A., El Hassan, L.A., et al. (2012) Schistosomiasis of the Spinal Cord: Report of 5 Cases from Sudan. Eastern Mediterranean Health Journal, 18, 294-297. https://doi.org/10.26719/2012.18.3.294 